\title{
The Vibration Characteristics of Diesel Engine Cylinder Piston Rings Under Different Wear
}

\author{
Yongchao Cheng*, Yaofei Li, Miao Zhang, Haihua Deng, Shuai Wang
}

The Second Ship Design Institute of Wuhan, Wuhan, China

Email address:

15997433862@126.com (Yongchao Cheng)

*Corresponding author

\section{To cite this article:}

Yongchao Cheng, Yaofei Li, Miao Zhang, Haihua Deng, Shuai Wang. The Vibration Characteristics of Diesel Engine Cylinder Piston Rings Under Different Wear. International Journal of Transportation Engineering and Technology. Vol. 7, No. 4, 2021, pp. 92-96.

doi: $10.11648 /$ j.jitet.20210704.11

Received: July 16, 2021; Accepted: October 25, 2021; Published: November 5, 2021

\begin{abstract}
In this paper, Through the experimental research on the wear of cylinder liner and piston ring of diesel engine under different forms, The purpose is to study the vibration law of piston ring of cylinder liner of diesel engine under different wear conditions, and obtain the vibration law through vibration signal analysis, which provides theoretical support for the design of diesel engine. The relevant laws are obtained, which provides good technical support for the follow-up design and research. to explore the use of vibration signals to monitor the cylinder piston ring wear state of the feasibility of starting, summed up the vibration signal of diesel engine piston ring and cylinder liner wear contact the specific state, According to the wear state of multiple sets of cylinder liner piston rings and the change trend of each characteristic parameters of vibration signal: As the wear of the piston ring increases, the vibration signal increases and the vibration characteristic parameters increases; The variation trend of each vibration characteristic quantity with the cylinder liner piston ring is basically the same, and it increases with the increase of wear quantity; When the amount of cylinder liner piston ring is large, the gap between them is also large. The increase of clearance causes the change of characteristic parameters greatly, otherwise it is smaller. Therefore, the larger the gap, the more reliable the diagnosis will be the vibration signal analysis cylinder piston ring wear state of the specific program for diesel engine maintenance and provides the basis for maintenance.
\end{abstract}

Keywords: Piston Ring and Cylinder, Wear, Vibration Signal, Time Domain Analysis, Frequency Domain Analysis

\section{Introduction}

Cylinder piston rings system is one of important components of diesel engine, as well as the worst component under working condition. The circumstance of high temperature, high pressure, high speed of moving direction, moving speed and lubricating oil makes the cylinder liner piston ring prone to wear fail, which has a significant impact on the work of internal combustion engine [1]. Therefore, it is very important to find a method that can monitor the wear condition on line so as to postpone cylinder liner piston rings wear fail and improve the life the internal combustion engine and its use benefit.

Generally, there are two ways to monitor the wear of cylinder piston rings in practical engineering application, they are oil monitoring and vibration monitoring. Oil monitoring method is to monitor the pollution state of lubricating oil, and analyze the physical and chemical indexes of impurities in lubricating oil by Ferrography or spectral analysis technology to analyze the wear state of cylinder liner piston ring to achieve the detection purpose. Meanwhile, the vibration monitoring method is to analyze the wear state of the cylinder liner piston ring by monitoring the abnormal vibration state of the body caused by the wear of the cylinder liner piston ring of the diesel engine, so as to achieve the purpose of monitoring the wear of cylinder liner piston rings [8-15]. In this paper, we research on vibration monitoring method.

In the process of piston ring working, wear will cause the change of clearance between cylinder liner and piston ring, and this change will cause the change of main impact parameters such as impact time and impact force of piston group, and the change of vibration response of fuselage, which makes it possible to use the vibration response signal of fuselage to monitor the wear state of cylinder liner and piston 
ring.[2] The purpose of this paper is to find out the vibration characteristics of the fuselage which reflect the wear condition of the cylinder liner piston ring, and to find a method to monitor the wear of the cylinder liner piston ring by using the vibration response of fuselage.

\section{Monitoring Principle of Wear Vibration of Cylinder Liner Piston Ring}

The wear between the piston rings of cylinder liners can be reflected by the clearance between them. When the clearance changes, under the same side thrust, the speed at which the piston impacts the cylinder liner will change, resulting in the change of impact energy. At the same time due to the change of the clearance, the lateral movement of the piston in the cylinder changes, resulting in the change of the impact times and positions of the cylinder liner. The cylinder vibration characteristic changes with the change of these excitation above. As the vibration of the fuselage is affected by the fluid shock, combustion shock, piston group impact and other multiple excitations, how to extract the characteristic quantity which can correctly reflect the wear of the piston ring from the complex signal is the key to identify the wear of the piston ring.

There are many excitations that cause fuselage vibration [3], generally the major excitation sources are: gas pressure, piston lateral impact force, periodic excitation of gas pressure and reciprocating inertia force of piston through connecting rod and crankshaft, other institutions and some random incentives.
The results show that: the effect of gas pressure is mainly in the low frequency part (within $500 \mathrm{~Hz}$ ); the effect of value mechanism motion shock only changes the number of peaks, but not the energy band of vibration; the energy of crankshaft is very small, and there is no obvious peak value of energy; the transverse impact of the piston has the most significant effect on the vibration of fuselage. It makes the fuselage vibrate in the frequency band near its natural frequency, and its change causes the obvious change of the vibration characteristics. Therefore, the transverse impact of the piston is the major excitation source of fuselage vibration. The response of piston impact can be easily identified although there are various excitations acting at the same time. [4] For some characteristic parameters of piston impact vibration signal reflect the interval state between piston ring and cylinder liner, the relationship between these characteristic parameters and interval can provide basis for diagnosis.

The main cause of the piston transverse movement is the side thrust of crank connecting rod mechanism. And the clearance between the piston and the cylinder liner is an important factor affecting the impact speed of the piston. During a working cycle, the change of side thrust near the top dead center at the beginning of expansion stroke is the most violent. At this time, the impact energy of piston on cylinder sleeve is the largest, so it is called the main impact. We can calculate the velocity of the main impact as well as crank angle in case of knowing side thrust force and the clearance between the cylinder liner and cylinder piston rings. The side thrust force of crank connecting rod mechanism can be expressed as formula below:

$$
F_{s}(t)=\left[P \pi D^{2} / 4-M \omega 2 R(\cos \omega t+\lambda \cos 2 \omega t)\right] \cdot \lambda \sin \omega t \cdot\left(1-\lambda^{2} \sin 2 \omega t\right)-1 / 2
$$

Where P-gas pressure in cylinder; D-diameter of cylinder; $\omega$-crank angular velocity; M-reciprocating mass; R- crank radius; $\lambda$-crank radius connecting rod radio.

Acceleration of piston transverse movement: $a(t)=F_{s}(t) / M$, velocity of piston transverse movement: $V(t)=\int_{t_{0}}^{t} a(t) d t$, displacement of piston transverse movement: $S(t)=\int_{t_{0}}^{t} V(t) d t$.

The piston starts to move from the movement when the side thrust reverses, impacts the cylinder liner through the clearance between the piston and cylinder liner. Therefore, when the movement displacement is equal to the clearance between the piston and the cylinder liner, the velocity of the piston hitting the cylinder is the velocity, and the crank angle is the impact point.

At fixed speed, the main impact velocity increases significantly with the increase of clearance. It is possible to use vibration signal of fuselage to estimate the clearance between piston ring and cylinder liner, due to the relationship of main impact and clearance between piton and cylinder liner, and furthermore main impact velocity can reflect the vibration level of fuselage as well as cylinder liner. In addition to the main impact velocity, the gap also affects the impact point. When the clearance increases, the crank angle of the main impact will lag.

The vibration signal can't be estimated to the clearance between piston and cylinder liner straightly, it must be processed and transformed properly so as to achieve the most sensitive and direct characteristic parameters. Then establish criterion to recognize and diagnose the clearance between the piston and cylinder liner by use of various knowledge and experience based on these characteristic parameters.

\section{Tribology and Dynamic Simulation Test System of Internal Combustion Engine}

The main components and monitoring parameters of the internal combustion engine tribology and dynamic simulation test system are as follows:

(1) components of cylinder and piston rings

Cylinder bore $105 \mathrm{~mm}$, stroke $115 \mathrm{~mm}$. Splash lubrication between cylinder liner and piston rings.

(2) main shaft sliding bearing part 
Standard single cylinder sliding bearing matched with cylinder liner (cylinder bore $105 \mathrm{~mm}$ ). The main shaft sliding bearing adopts a lubrication system to realize hydrodynamic lubrication. The lubrication system is composed of oil pump, filter, cooler, oil pressure, oil gauge, etc. an oil groove is installed in the lubrication system for inspection.

(3) axial loading part

The crankshaft connector leads out the main shaft power for axial load test to isolate the influence of axial load on the right sliding bearing; Adopt step motor and spring loading mode to ensure stable and accurate loading.

(4) main shaft power part

Selection of motor; $15 \mathrm{~kW}$ motor, $1600 \mathrm{rpm}$, variable frequency speed governor $15 \mathrm{~kW}$, control speed between 100 rpm and $2000 \mathrm{rpm}$, considering the estimated cylinder compression ratio is $16: 1$, install inertia wheel with $1 \mathrm{MPa}$ input compressed air according to 4 stroke.

(5) the main measuring parts and requirements are listed as follows:

Table 1. Main functions of the simulation test system of internal combustion engine.

\begin{tabular}{llll}
\hline Measuring position & Measuring parameters & Sampling method & Control and display \\
\hline \multirow{2}{*}{ Cylinder liner -piston ring } & Temperature, pressure, vibration, oil & Take oil sampling through specific & analog signal of the pressure and temperature of \\
& sampling & cylinder lubricating oil box & oil sampling \\
Main sliding bearing & Oil temperature, friction, vibration, & Lubrication system independent & analog signal of Temperature, friction, rotation \\
oil sampling from lubrication system & on crankcase & rate, revolutions, vibration VS time & Analog signal of axial force, friction, vibration \\
\hline
\end{tabular}

The physical diagram of internal combustion engine simulation test system is shown in the figure 1:

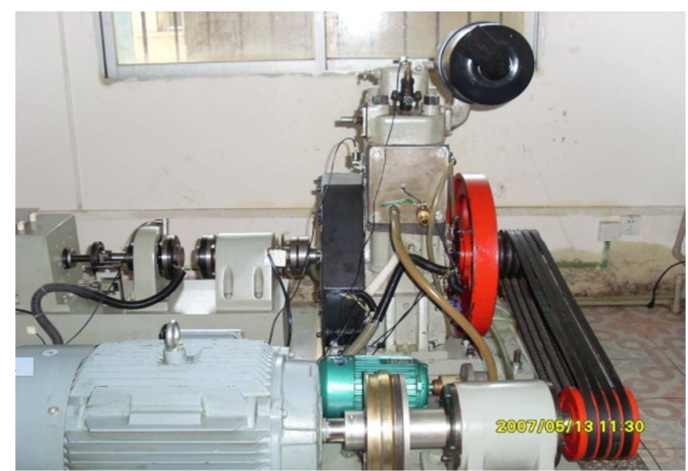

Figure 1. Tribology and dynamics simulation system of internal combustion engine.

\section{Wear Status of Cylinder Liner Piston Rings}

It can be seen from the principle of PQP that the magnetism of abrasive particles in oil sample mainly includes: diamagnetism, paramagnetism, ferromagnetism. Fanhu abrasive tester can quickly detect the concentration of ferromagnetism abrasive particles (mainly iron, nickel and their alloys) in the oil, and can detect whether there are large abrasive particles in the oil sample. The PQ index obtained by PQP abrasive concentration. By continuously measuring the PQ index of samples taken from the equipment at different operation times and making the curve of its relationship with operation time, the development trend of the equipment wear state can be evaluated. [5]

In the test, the sample of lubricating oil in diesel engine is taken every time, and PQP is used to analyze the wear state of cylinder internals. The data about the wear of cylinder liner piston ring is shown in Chart 2, and the sampling period is 6 hours.
Table 2. $P Q P$ of sampling lubricating oil.

\begin{tabular}{llll}
\hline Sampling number & PQP & $\mathbf{1 1}$ & $\mathbf{4 6 . 8}$ \\
\hline 1 & 7.6 & 12 & 39.4 \\
2 & 20.4 & 13 & 34.2 \\
3 & 21.2 & 14 & 36.8 \\
4 & 28.2 & 15 & 42.4 \\
5 & 26.8 & 16 & 48 \\
6 & 17.6 & 17 & 52.6 \\
7 & 25.6 & 18 & 53.4 \\
8 & 25 & 19 & 56.4 \\
9 & 29.8 & 20 & 70.2 \\
10 & 41.2 & 21 & 57.4 \\
\hline
\end{tabular}

According to the results of PQP analysis, the wear condition of the cylinder liner piston ring as the test goes on, and the wear curve is as shown in Figure 2.

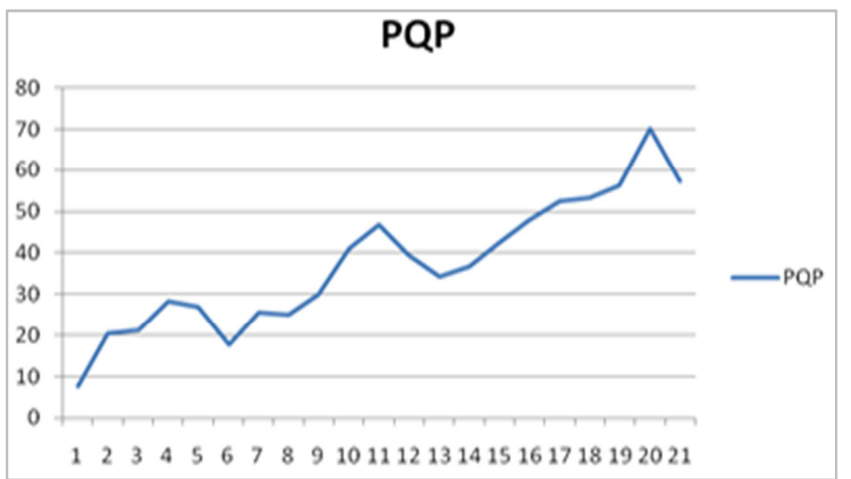

Figure 2. $P Q P$ curve of lubricating oil.

\section{Vibration Characteristics in Time and Frequency Domain}

On the tribology and dynamics experimental system of internal combustion engine, the vibration characteristics change during the wear process of cylinder liner piston ring of diesel engine is tested. The sampling period is 6 hours. After each sampling, the positive and negative peak value, root 
mean square value and vibration frequency are obtained. The recorded data are shown in Chart 3.

Table 3. Characteristic value of vibration signal.

\begin{tabular}{lllll}
\hline Sampling number & maximum & minimum & RMS & Frequency \\
\hline 1 & 4.64 & -5.115 & 0.1735 & 10.26 \\
2 & 1.653 & -0.316 & 0.0737 & 9.883 \\
3 & 2.029 & -0.338 & 0.077 & 9.798 \\
4 & 5.127 & -0.378 & 0.1552 & 9.918 \\
5 & 5.112 & -5.092 & 0.2034 & 10.196 \\
6 & 2.735 & -0.34 & -0.108 & 9.919 \\
7 & 4.011 & -5.126 & 0.1818 & 9.509 \\
8 & 5.106 & -0.355 & 0.1448 & 10.056 \\
9 & 5.133 & -0.524 & 0.1759 & 10.224 \\
10 & 5.131 & -2.126 & 0.1379 & 9.6025 \\
11 & 5.125 & -1.827 & 0.1444 & 9.289 \\
12 & 5.122 & -0.391 & 0.1265 & 9.559 \\
13 & 0.741 & -0.668 & 0.2208 & 2.283 \\
14 & 1.901 & -0.692 & 0.2233 & 29.759 \\
15 & 5.061 & -0.62 & 0.2519 & 29.877 \\
16 & 0.63 & -0.327 & 0.068 & 9.792 \\
17 & 0.314 & -0.19 & 0.0332 & 9.351 \\
18 & 0.438 & -0.241 & 0.0644 & 9.721 \\
19 & 0.667 & -0.395 & 0.1249 & 10.636 \\
20 & 0.396 & -0.237 & 0.0751 & 28.675 \\
21 & 0.607 & -0.219 & 0.0756 & 3.516 \\
\hline
\end{tabular}

According to the data records, it is easy to get the maximum and minimum value of vibration amplitude, RMS value and vibration frequency of the vibration signal of the diesel engine under the condition that cylinder liner piston ring is constantly worn with the operation of the diesel engine, as shown in figures 3 6.

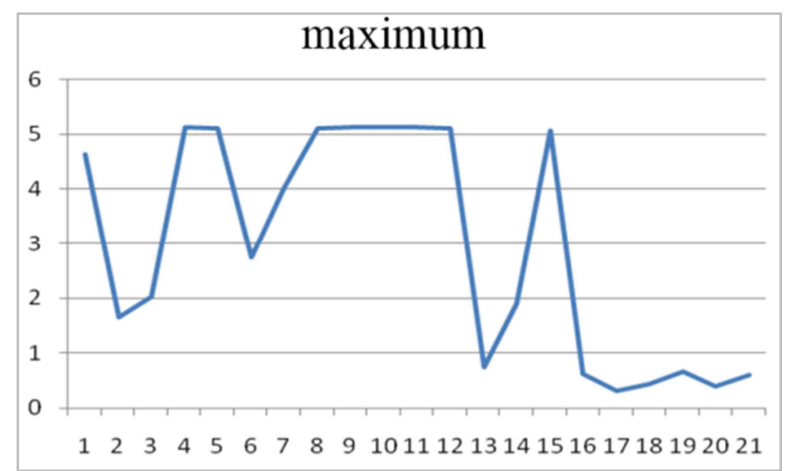

Figure 3. Maximum amplitude curve.

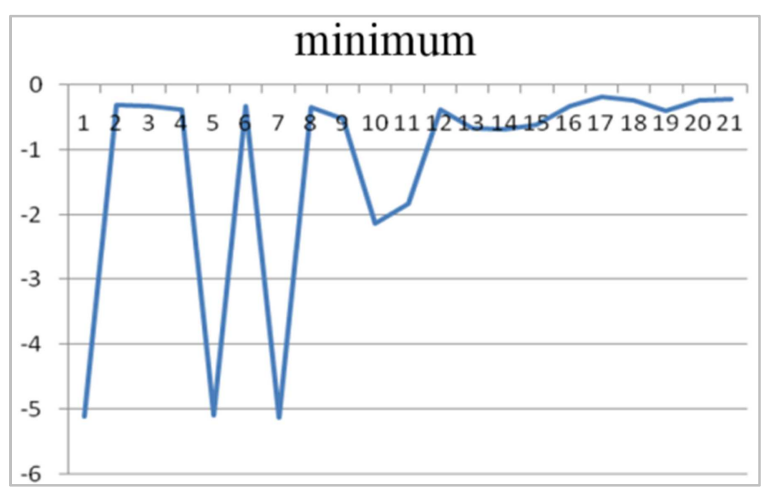

Figure 4. Minimum amplitude curve.

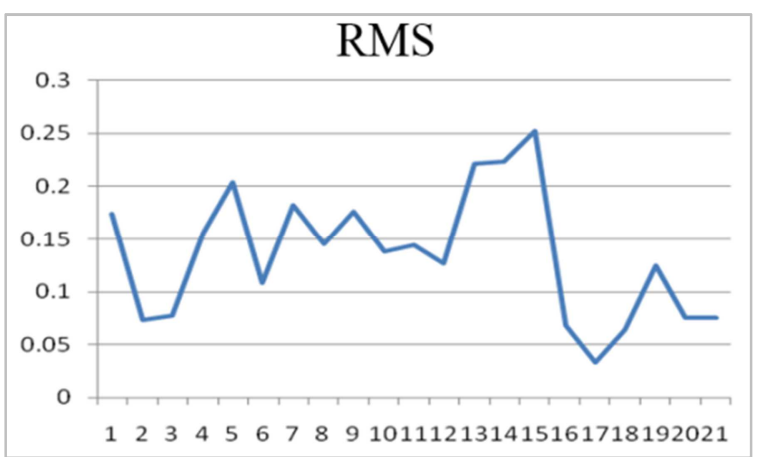

Figure 5. RMS curve.

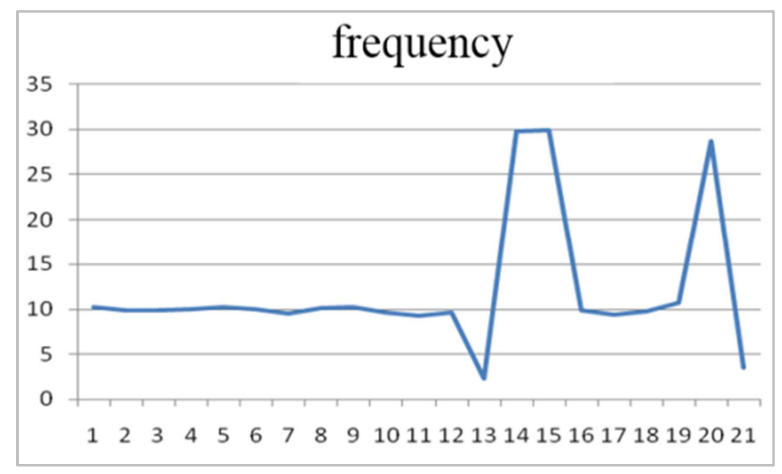

Figure 6. Frequency value curve.

\section{Analysis of Test Results}

In the running-in stage of diesel engine, the wear between piston ring and cylinder liner is very strong, for the surface roughness of them is large. After running in and reaching the normal technical condition, the wear is slow and even in a long working time due to the good fit between mating parts and the improvement of lubrication conditions. Finally, when the cylinder clearance exceeds a certain value because of wear, the wear is intensified due to the leakage of gas and oil, the knocking of moving parts and other factors. The wear condition of cylinder liners is different along the height direction, and the size of wear varies with the temperature, pressure and lubrication conditions. [6] The worst wear occurs near the first piston ring when the piston is at TDC, in the case of normal wear. Because of the high temperature, the poor lubrication conditions, the wear resistance of the metal is reduced, and because of the role of gas, the pressure of piston on the inner wall of the cylinder is also the largest. The oil film in the middle of the cylinder sleeve is rich, which can maintain favorable lubrication conditions and protect the cylinder sleeve from serious wear and corrosion, so the wear is relatively small. When the piston is near the BDC, the oil film is not easy to form due to the low sliding speed, and thus the wear of the cylinder sleeve is slightly larger than that of the middle part. Due to the poor use and maintenance or other human factors, the cylinder liner can be subject to a large amount of wear in a short period of time, which is called abnormal wear. [7] E.g. wear when air cleaner is inefficient or short circuited, wear caused by poor filtration or deterioration of engine oil. When the diesel engine uses high sulfur fuel or 
starts the channel at low temperature, corrosion and wear will occur. The first piston ring is strongly corroded near the TDC, and the wear amount is $1 \sim 2$ times larger than the normal wear, meanwhile, the wear of the middle part also increases by $4 \sim 6$ times mainly due to abrasive wear caused by corrosion of exfoliated metal particles.

We can conclude from the trend of vibration of peak, RMS, frequency that PQP of the lubricating oil rises along time, actually it is a process of continuous accumulation considering abrasive particle of lubricating oil.[6] Therefore, the cylinder liner ring of the diesel engine is under the process of smooth from PQP index change. The maximum and minimum vibration peak fluctuate greatly in the early stage, but trend to be stable in the later stage; the RMS value of vibration signal is consistent with the fluctuation of the lubricating oil curve, but the RMS value fluctuates in a fixed range, and the frequency of the vibration signal is relatively stable at initial stage, but it fluctuates greatly at the larger stage.

During the running in period of diesel engine, the vibration signal amplitude of the fuselage fluctuates greatly due to the large surface roughness and strong wear of the cylinder liner piston ring, but the vibration frequency is in a small fluctuation state due to the small fit clearance. When enters the normal working state, the lubrication condition is improved, and the fit is good. Therefore, the vibration amplitude displayed on the vibration signal of the fuselage tends to be stable, and the amplitude is small, but the vibration frequency tends to be unstable due to the continuous increase of the fit clearance.

\section{Conclusion}

According to the wear state of multiple sets of cylinder liner piston rings and the change trend of each characteristic parameters of vibration signal, the following conclusion can be drawn:

(1) As the wear of the piston ring increases, the vibration signal increases and the vibration characteristic parameters increases;

(2) The variation trend of each vibration characteristic quantity with the cylinder liner piston ring is basically the same, and it increases with the increase of wear quantity;

(3) When the amount of cylinder liner piston ring is large, the gap between them is also large. The increase of clearance causes the change of characteristic parameters greatly, otherwise it is smaller. Therefore, the larger the gap, the more reliable the diagnosis will be.

\section{References}

[1] Zhu Hua, Zhao Yong. Causes and prevention of piston ring wear in diesel engine. Lubrication and sealing, 2006, 2: 186 191.

[2] Xie Xihua, Yuan Donglai, Hao Peng. Study on failure vibration of piston ring. Noise and vibration control, 2008, 4 (2): $132 \sim 134$.

[3] Yang Ji, Yang Guiheng, Zhang Shouzhen. Research on abnormal wear mechanism and preventive measures of cylinder liner of internal combustion engine. Internal combuston engine, 2007 (2): 15 18.

[4] Xu Yiyong, Yang Jianguo. Diagnosis of engine piston cylinder liner wear clearance by vibration analysis. Wuhan shipbuilding, 1997, 3: 31 36.

[5] Song Bingkun, Wang Wenzhong, Wang Hui, Hu Yuanzhong. Experimental study on wear characteristics of engine cylinder liner and piston ring. Lubrication and Sealing, 2004. 3: 29 32.

[6] Huang Qiang, Song Shihua, Ding Zhihua, Liu Xin. Research on fault degree of diesel engine based on Vibration Analysis. Journal of Huazhong University of science and technology (natural science edition), 2007, 35 (6): 105 107.

[7] Chen Xinzhi. On the method transient vibration analysis. Journal of Northwest Institude of light industry, 1994, 9: $161 \sim 167$.

[8] Zhu Jianyuan, marine diesel engine, Beijing: People's Communications Press, 1997.

[9] Zhou Mingshun, marine diesel engine, Dalian: Dalian Maritime University Press, 2007.

[10] Han Shoujia, general idea of shipbuilding, Dalian: Dalian Maritime University Press, 1993.

[11] Jiang Weiqing, ship principle, Beijing: People's Communications Press, 1992.

[12] Zhou Weijie, turbine maintenance and repair, Beijing: People's Communications Press, 2002.

[13] China Classification Society, code for naturalization of steel seagoing ships, 2004.

[14] Yu Hongliang, technical management of marine power plant, Dalian: Dalian Maritime University Press, 2009.

[15] Shi Meitang, metal materials and heat treatment, Shanghai: Shanghai Science and Technology Press, 2009. 